\title{
TALENTOS PERDIDOS: LIVRO DIGITAL INTERATIVO PARA O DEBATE DO TEMA DST/AIDS
}

L. M. C. T. NASCIMENTO ${ }^{1}$, R. C. FRENEDOZO ${ }^{2}$, J. SCHIMIGUEL ${ }^{3}$, N. A. C. LACERDA ${ }^{4}$, M. H. O. LACERDA ${ }^{5}$, N. S. L. SILVA $^{6}$, C. S. SILVA

Instituto Federal de Educação, Ciência e Tecnologia de Goiás ${ }^{1,4,5,7}$, Universidade Cruzeiro do Sul2,3, Universidade Federal de Uberlândia ${ }^{6}$ lucycmb@gmail.com ${ }^{1}$

Artigo submetido 01/03/2016 e aceito 09/01/2019

DOI: $10.15628 /$ holos.2019.4192

\section{RESUMO}

As Tecnologias da Informação e Comunicação por meio dos recursos da plataforma web 2.0 podem colaborar para um processo educativo mais interativo e dinâmico. Este artigo objetivou avaliar as contribuições de um livro digital interativo, elaborado por licenciandos em Ciências Biológicas sobre o tema AIDS, para a aprendizagem de alunos do ensino fundamental anos finais. A metodologia quanti-qualitativa foi adotada nesse estudo sendo realizado um pré-teste e um pósteste com alunos do 80 ano do ensino fundamental de uma escola pública divididos em um grupo controle e outro experimental. Os dados submetidos ao teste de hipóteses bicaudal para duas amostras independentes e variáveis utilizando a distribuição $t$ de student demonstrou que os alunos que utilizaram o livro digital conseguiram entender melhor a importância e os meios de prevenção da AIDS, demonstrando estatisticamente melhor desempenho na avaliação com significância superior a $5 \%$. Além disso, os resultados apontaram que os alunos pouco discutem sobre DST na escola e na família, sendo necessário ampliar o debate e o acesso à informação para esse público, bem como promover eventos na escola que para que esse assunto seja também discutido com os pais.

PALAVRAS-CHAVE: tecnologias, formação de professor, ensino de ciências.

\section{LOST TALENTS: DIGITAL INTERACTIVE BOOK TO DEBATE THE ISSUE DST/AIDS}

\begin{abstract}
The information and communication technologies using features based on the web 2.0 platform may contribute to a more interactive and dynamic educational process. This article aims to evaluate the contributions of an interactive ebook, written by undergraduates in Biological Sciences on the subject of AIDS, used on teaching in elementary school's final years. The quantitative and qualitative methodology was adopted in this study, a pre-test and a post-test were done with 8th graders of elementary education at a public school, they were divided into a control and an experimental group. The data gathered were submitted to two-tailed
\end{abstract}

hypothesis test using two independent and variable samples utilizing the $t$ distribution showed that students who used the ebook were able to have a better understanding of AIDS prevention methods and its importance, displaying better performance in the ratings with a significance value of more than $5 \%$. In addition, the results showed that students do not talk about STDs in school or with their families, so it is necessary to expand the debate of the matter and make access to information easier for this audience as well as promote events at the school so that this issue can also be discussed with the parents.

KEYWORDS: technologies, teacher training, science teaching. 


\section{APRESENTAÇÃo}

Plenamente incorporadas à dinâmica e à cultura da sociedade atual, as Novas Tecnologias da Informação, Comunicação e expressão (NTICE) proporcionam também uma nova relação dos agentes evolvidos no processo de ensino-aprendizagem (Garcia; Lins, 2008; Fey, 2011). Nascidos em uma sociedade com estes avanços, grande parte da geração de alunos está perfeitamente ambientada com essa nova linguagem digital e com os novos padrões de pensamento característicos dessas tecnologias, sendo denominados então, como nativos digitais (Prensky, 2001).

Contudo, o referido autor alerta que os professores, acostumados com a dinâmica préera digital sem grandes mudanças e aprendizagens contínuas, por isso, denominados de imigrante digitais, muitas vezes não enxergam novas possibilidades de ensino com essas ferramentas. Um dos motivos pode estar atrelado ao fato de não dominarem essa linguagem.

Há de se ressaltar que os imigrantes digitais são aprendizes visuais e se envolvem muito mais com o conteúdo de aprendizagem quando este proporciona recursos multimídia de fácil manipulação que podem estar presentes, por exemplo, em um livro digital (Amorim e Bianco, 2011).

As NTICE têm evoluído e proporcionado a seus usuários maiores oportunidades de interação e produção de conteúdo graças às plataformas da Web $2.0^{1}$. Além disso, as mídias digitais são responsáveis por transformações culturais que interferem na forma como crianças e jovens se relacionam com o conhecimento e com a cultura (Fernandes, 2010). Dessa maneira, a diversidade cultural proporcionada por elas impacta também as relações humanas em diversos setores, seja no âmbito escolar, familiar, econômico, profissional e, sobretudo no lazer.

Outra possibilidade apresentada por Fey (2011) é que esse tipo de recurso é capaz de contribuir para os processos de ensino e de aprendizagem por intermédio de uma linguagem atrativa, uma vez que permite combinar vários efeitos audiovisuais que atraem a atenção dos alunos, principalmente se comparados com as aulas tradicionais de escrita e fala.

Além da atratividade, as NTICE possibilitam um elemento característico destas novas tecnologias: a interatividade, visando proporcionar ao aluno um papel ativo na busca de conhecimento, rompendo desta forma com a passividade que tradicionalmente lhe foi conferida (Valle \& Bohadana, 2012).

No contexto do mundo globalizado, no qual despontam a comunicação em rede, a leitura e escrita ganham a dimensão virtual. Dessa forma, a leitura e a escrita saltam para as telas dos dispositivos midiáticos, como os celulares, os smartfones, os tablets e a tela dos computadores. Todavia, apesar dos jovens, nativos digitais, estarem constantemente conectados por meio dos seus dispositivos ligados a internet e terem acesso a inúmeras mídias de informação e comunicação, isso não tem se traduzido em conhecimento acadêmico. De acordo com o Programa Internacional de Avaliação de Estudantes - PISA de 2009 o Brasil tem se destacado por seus resultados lamentáveis, visto que, $60 \%$ dos alunos brasileiros, em média

\footnotetext{
1 O termo web 2,0 é atribuído a empresa americana O"Reilly Media e é caracterizado pela apropriação mais
} interativa e colaborativa dos usuários e provedores das redes digitais. 
com 15 anos, que fizeram a prova não demonstraram competências mínimas para resolver problemas simples do cotidiano que exigiam habilidades de leitura e matemática (Brasil, 2010).

Podemos melhor compreender esses dados ao analisarmos a pesquisa realizada por Haag (2012) entre 2008 e 2010, em 9 mil escolas da América Latina (incluindo o Brasil) e Espanha. Ele descreve que apesar dos jovens acharem o conhecimento científico importante, eles manifestaram que disciplinas como biologia, química, física, e matemática são difíceis, chatas e acreditam terem um campo de emprego limitado, ou seja, não permitem diversificar. Os entrevistados reclamavam ainda do modo como essas disciplinas eram ensinadas e também sobre os recursos utilizados.

Considerando a perspectiva de envolver o aluno no processo de ensino-aprendizagem, os Parâmetros Curriculares Nacionais (PCN) alertam sobre a possibilidade de integrar nos conteúdos escolares temas sociais relevantes, como a orientação sexual e a saúde do indivíduo em processo de formação (Brasil, 1998). Abordar estas questões com o aluno é de suma importância para que ele seja capaz de conhecer, compreender e fazer escolhas que contribuam para uma vida saudável (Brasil, 1998). Percebe-se, então, a possibilidade de se trabalhar nas escolas os diversos aspectos relacionados às DST, tais como: sintomas, forma de transmissão e tratamento, aliados aos recursos tecnológicos.

Uma das DST que merecem destaque é a Síndrome da Imunodeficiência Adquirida (AIDS). De acordo com estimativas realizadas pelo Departamento de DST, AIDS e Hepatites Virais, "aproximadamente 718 mil pessoas vivem com o vírus da Imunodeficiência Humana HIV" (Brasil, 2013). Trata-se de um número alarmante, principalmente se considerarmos que as mídias, principalmente a televisiva, constantemente divulgam informações de prevenção a respeito da AIDS e do HIV.

Muito mais que um problema de cunho epidemiológico, a AIDS abrange dimensões sociais, políticas e culturais, mobilizando e integrando movimentos sociais, áreas científicas e alavancando as discussões sobre sexualidade (Galvão, 2000). Tal temática exige, portanto, ser discutida principalmente junto aos jovens, que estão em processo de formação intelectual e física.

Lidar com tais demandas implica em capacitar os alunos para usufruírem adequadamente das informações disponibilizadas, inclusive as difundidas por meio dos recursos digitais e os docentes desde a sua formação inicial para lidar com esses problemas e a necessidade de incorporar no processo educativo metodologias envolvendo recursos tecnológicos.

Dessa maneira, no intuito de se buscar uma nova estratégia metodológica que rompesse com a falta de interatividade imposta por uma abordagem tradicional das DST que geralmente ocorre nas escolas e reconhecendo as características inerentes à geração de nativos digitais, buscou-se produzir um livro digital interativo sobre o tema AIDS. O intuito foi avaliar suas contribuições no ensino e na aprendizagem de alunos dos anos finais do ensino fundamental sobre a temática apresentada. 


\section{A FORMAÇÃO DOCENTE PARA O USO DAS TICS}

Se considerarmos a escola como ambiente de formação de cidadãos para atuarem conscientemente na sociedade, esta deve proporcionar aos alunos de todas as fases, sua plena interação social e isso envolve usufruir do potencial ofertado pelas tecnologias digitais (Pontes, 2002). Trata-se, portanto, de desenvolver habilidades e competências específicas para lidar com a informação e isso implica um novo espaço de atuação do professor, o virtual.

Segundo Moran (2004, p.1) essa atuação exige do docente o gerenciamento dos múltiplos espaços de aprendizagem, integrando-os de "forma aberta, equilibrada e inovadora", seja a sala de aula, o laboratório, as pesquisas de campo, os projetos ou as atividades à distância intermediadas pela internet, de maneira a dar sentido ao que é ensinado e aprendido.

Destaca-se nesse processo a importância de capacitar os docentes na promoção da sua capacidade de autoria, pois ele é capaz de identificar as peculiaridades e necessidades dos seus alunos, dessa maneira pode e deve produzir material didático personalizado a esse público.

Nesse sentido, as NTICE proporcionam essa possibilidade, principalmente nos últimos anos, uma vez que, com o desenvolvimento tecnológico os sistemas de autoria passaram a exigir dos usuários menor conhecimento de linguagem técnica e proporcionarem aprendizagem interativa dos comandos permitindo "ao professor sem grandes conhecimentos de programação planejar e desenvolver seu material educativo" (Falkembach, 2005, p.2).

Isso não implica que se desconsidere a importância de conhecimentos na área de programação, tampouco negar a validade e o espaço de cursos voltados ao manuseio de determinados programas e recursos digitais, mas cabe aqui destacar que o uso das tecnologias digitais deve ser incentivado desde a formação inicial dos docentes.

Uma das ferramentas digitais utilizada pelos professores para exibição de imagens e informações é PowerPoint. Contudo, devido a grande disponibilidade de materiais prontos na rede mundial de computadores, muitos professores pegam apresentações prontas e às vezes descontextualizadas da realidade sociocultural de seus alunos. Mesmo os que elaboram suas apresentações, em diversas situações utilizam apenas alguns recursos básicos desse recurso.

Na pesquisa de Honório (2007) com professores universitários $77 \%$ dos participantes afirmaram não terem tido cursos voltados ao uso desse recurso, o que demonstrou correlação a um desconhecimento desses docentes das regras de apresentação utilizando de PowerPoint. Apesar disso, o PowerPoint pode representar um importante instrumento de autoria, de ensino e de aprendizagem, principalmente ao utilizar os diversos recursos multimídia, correlacionando sons e imagens e ainda, inserindo botões de ações que permitem maior interação do usuário.

Esta pesquisa volta-se nesse propósito, avaliar as contribuições de um livro digital interativo sobre o tema AIDS, elaborado por licenciandos em Ciências Biológicas utilizando os recursos do PowerPoint.

\section{METODOLOGIA}


O presente trabalho pautou-se em uma pesquisa quanti-qualitativa, pois a abordagem qualitativa favorece ao pesquisador aprofundar questões de compreensão, já a abordagem quantitativa possibilita estabelecer comparações de variáveis por meio de testes estatísticos. Assim os aspectos quanti e qualitativos permitem-nos melhor explorar os objetivos dessa pesquisa.

Nesse processo nos orientamos segundo as recomendações de Minayo et al. (2007) para a qual o processo de trabalho científico se divide em: fase exploratória; trabalho de campo e análise do material empírico e documental, correspondendo respectivamente às seguintes etapas:

1- Produção do livro digital.

2- Intervenção, que consistiu em comparar dois grupos de alunos, um grupo experimental e um grupo controle.

3- A análise foi realizada considerando a avaliação quanti-qualitativa realizada pelos alunos. Para isso utilizamos dois questionários semiestruturados, aplicado antes e após a intervenção.

Cada uma dessas etapas é descrita a seguir, nos tópicos: Apresentando o material produzido, Descrevendo a intervenção e Avaliando a intervenção.

\section{APRESENTANDO O MATERIAL PRODUZIDO}

O livro digital interativo foi produzido por discentes da Licenciatura em Ciências Biológicas, do Instituto Federal de Educação, Ciência e Tecnologia de Goiás, Campus Formosa durante o estágio supervisionado obrigatório.

A produção do livro consistiu em três etapas: discussão de personagens e enredo; produção da história e, produção do livro. Para isso foi utilizado o software Microsoft Office PowerPoint do sistema windows. Apesar de ser um recurso simples permite a inserção de botões de ação possibilitando ao desenvolvedor traçar estratégias que permitam maior interação do usuário.

Martinez, Fujihara e Martins (2008) relatam sobre a experiência da criação de jogos em PowerPoint para o ensino de genética destacam a importância dos professores em saberem utilizar melhor as ferramentas desse software para modificarem e criarem seus próprios jogos. O mesmo se aplica a produção de histórias interativas, pois cabe ao professor atuar também na produção de seus recursos didáticos, a fim de tentar aproximar-se da realidade dos seus alunos e das necessidades detectadas.

Nesse sentido, nessa proposta optamos por representar os personagens por meio de memes, desenhos muito utilizados em redes sociais e que fazem parte do cotidiano dos alunos. Já os diálogos foram adaptados de modo semelhante aos de uma história em quadrinhos. Foram também utilizados recursos audiovisuais para proporcionar maior interesse e interação dos alunos durante a leitura, como: efeitos criados com a inserção de links que permitem ao leitor avançar ou retroceder na história e também ouvir sons e ver efeitos de imagens.

Nas figuras 1 e 2, temos o print de duas páginas do livro nas quais se pode observar que o aluno pode interagir com o texto e explorar outros recursos como ouvir sons.

$\mathrm{Na}$ história, um grupo de alunos e alunas, que fazem parte respectivamente de um time de futebol e de uma torcida organizada, se envolve em tramas amorosas e no mundo das 
drogas, e assim acabam se deparando com a realidade de poderem estar contaminados com o vírus da AIDS.

Além de abordar de forma contextualizada os principais sintomas e enfermidades que vêm a se desenvolver em um indivíduo aidético, no livro são apresentados os meios de transmissão, prevenção e tratamentos para a doença.

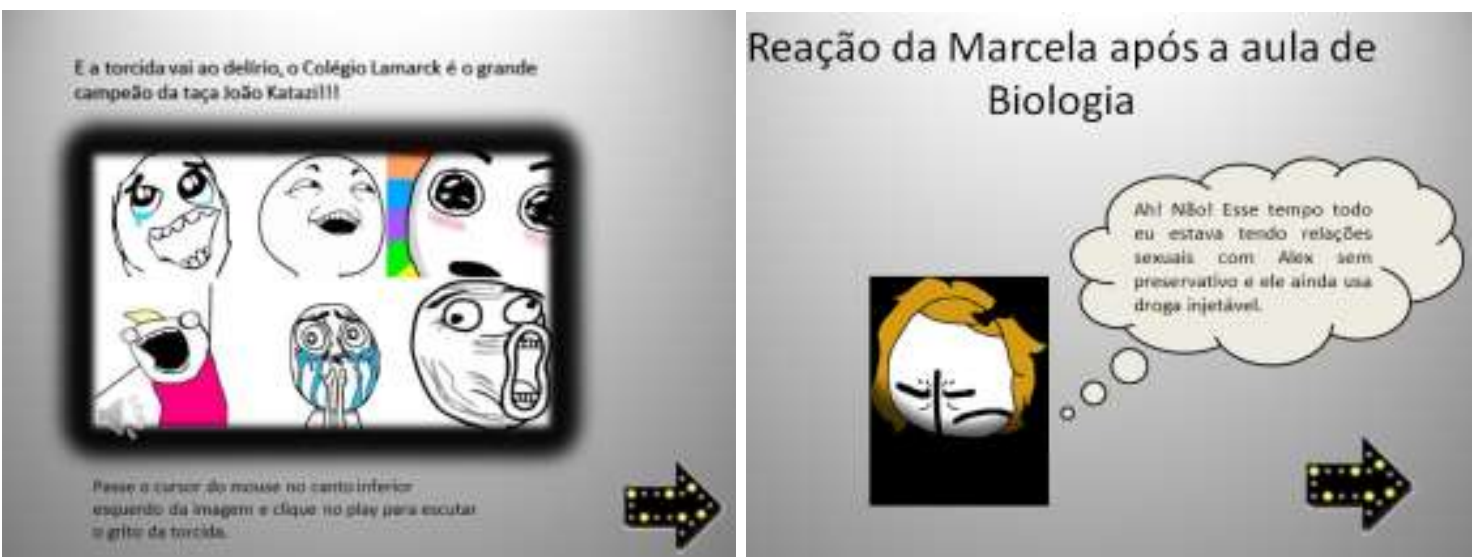

Figura 1 e 2: Páginas do livro "Talentos perdidos".

\section{DESCREVENDO A INTERVENÇÃO}

Para procedermos à intervenção, os alunos da licenciatura procuraram uma das escolas públicas do município de Formosa-GO concedente de estágio supervisionado. A primeira escola procurada não aceitou a intervenção alegando que os pais não aceitariam a discussão da temática em pauta. Esclarecemos que essa temática faz parte do currículo dos alunos do 8 ano do ensino fundamental para a qual a atividade foi proposta.

Com isso, os licenciandos procuraram outra escola e encaminharam aos pais e/ou responsáveis um termo de esclarecimento e livre consentimento para que os alunos participassem da pesquisa. De uma turma de 30 alunos, foram recebidas apenas 16 devolutivas, constituindo assim o público da pesquisa.

Esses alunos foram então divididos em dois grupos equitativos: um experimental, que utilizou o livro digital e um controle, que teve aula de forma tradicional usando para isso a exposição de textos e imagens por intermédio de PowerPoint e projetor. Ambos os grupos responderam, antes de cada intervenção, a um pré-teste contendo 9 questões objetivas e subjetivas com a finalidade de verificar o entendimento sobre o que é AIDS; sobre a diferença entre AIDS e HIV; sobre contaminação e formas de prevenção. Verificou-se, além disso, se a escola e a família abordavam com eles esses temas.

A aula com o grupo controle ${ }^{2}$ foi realizada na sala de aula, já o outro grupo experimental foi conduzido ao laboratório de informática. Contudo, como não havia computadores em

\footnotetext{
${ }^{2}$ Esclarecemos que o grupo controle posteriormente teve acesso ao livro digital interativo.
} 
número suficiente e com pacote Office para a utilização do livro elaborado no Power Point, foi necessário levar notebooks para a execução dessa atividade. Dessa forma, os alunos formaram 4 duplas para poderem interagir com o respectivo material.

No quadro 1, apresentamos as questões aplicadas aos alunos no pré-teste e no pósteste, sendo as questões 7, 8 e 9 apresentadas apenas no pós-teste do grupo experimental e à questão 5 apresentada apenas no pré-teste.

Quadro 1- Teste aplicado aos alunos

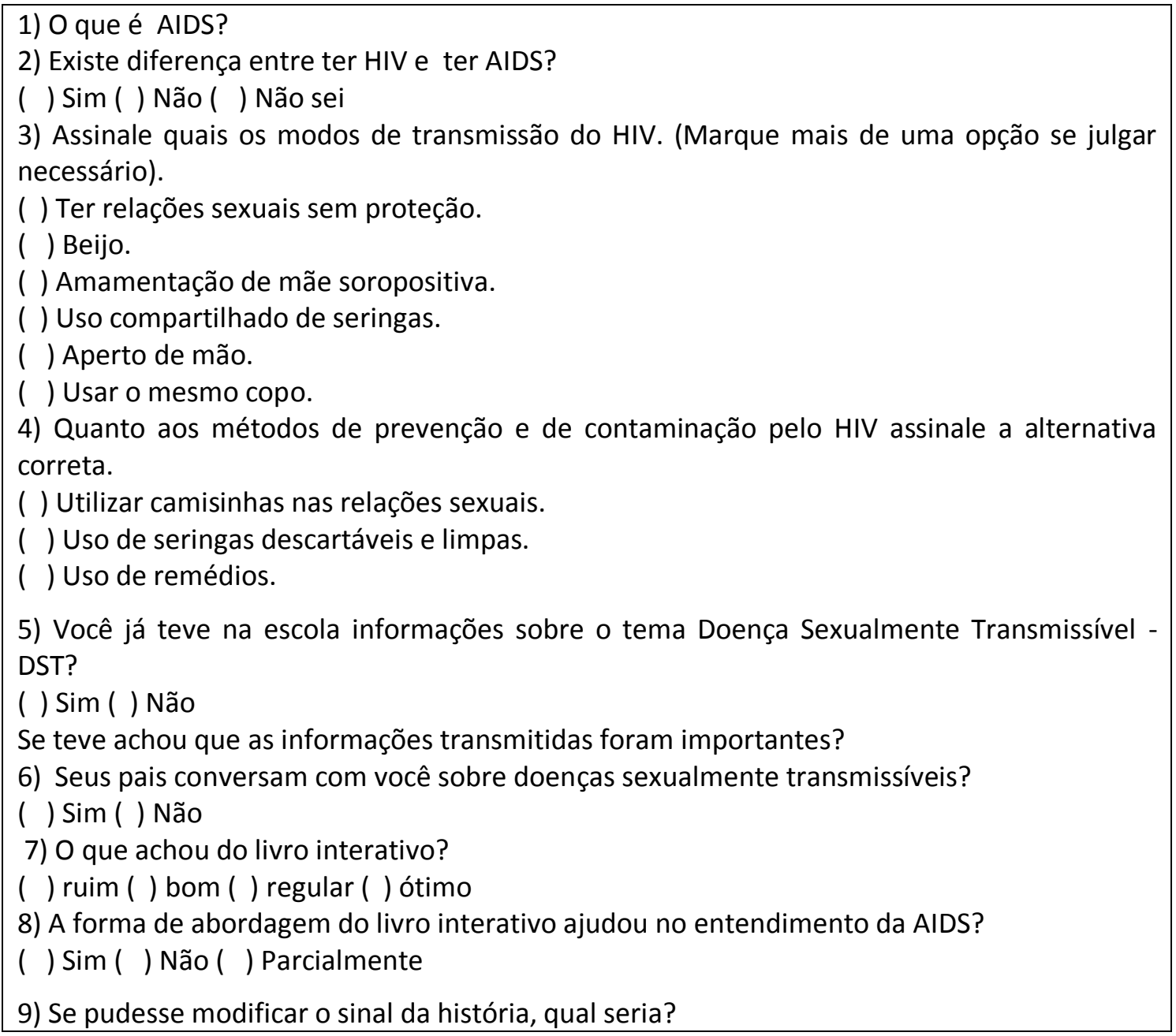

\section{AVALIANDO A INTERVENÇÃO}

Objetivando fornecer informações sobre o conhecimento dos alunos, sobre o tema DST/AIDS, antes e após a intervenção e possibilitar melhor discussão e confronto dos resultados, a aprendizagem dos alunos foi verificada por meio dos questionários, aplicados antes e após a intervenção.

Cada questionário foi avaliado em 10 pontos. As questões de 1 a 4 pontuaram 2,5 cada, cada uma das três opções corretas da questão 3 valeu 0,3 , e cada opção correta da questão de número 4 valeu 0,8. A questão 5 não foi pontuada, mas foi considerada. As questões de 7 a 9 presentes apenas no pós-teste do grupo experimental também não foram pontuadas. 
Na tabela 1, podemos observar as médias dos pré-testes e dos pós-testes dos alunos do grupo controle, evidenciando que a média com uso do multimídia melhorou após a intervenção, aumentando 0,75 pontos, uma diferença nas médias de 13,64\% em relação ao pré-teste. Contudo, dois alunos mantiveram a mesma média e um obteve resultado inferior.

Tabela 1- Médias pré e pós-testes dos alunos do grupo controle

\begin{tabular}{ccrrrrrr}
\hline Aluno 1 & \multicolumn{1}{c}{ Aluno 2 } & Aluno 3 & Aluno 4 & Aluno 5 & Aluno 6 & Aluno 7 & Aluno 8 \\
\hline 4,0 & 6,5 & 5,5 & 5,5 & 5,5 & 5,0 & 6,0 & 6,0 \\
5,0 & 6,5 & 6,5 & 8,5 & 5,0 & 5,0 & 6,5 & 7,0 \\
\hline Total pré-teste: 44,0 & & & & & Média pré-teste $=5,5$ \\
Total pós-teste: 49,0 & & & & & Média pós-teste $=6,25$ \\
\hline
\end{tabular}

Na tabela 2, apresentamos os resultados das médias pré-teste e pós-teste dos alunos do grupo experimental. Podemos observar que os alunos também apresentaram um aumento nas médias de 1,05 pontos, ou seja, correspondendo a uma diferença das médias de 14,78\% e somente um deles teve resultado inferior ao pré-teste.

Tabela 2- Médias pré e pós-testes dos alunos que utilizaram o livro digital

\begin{tabular}{llcccccc}
\hline Aluno 1 & Aluno 2 & Aluno 3 & Aluno 4 & Aluno 5 & Aluno 6 & Aluno 7 & Aluno 8 \\
\hline 10,0 & 5,5 & 6,5 & 9,0 & 4,0 & 6,5 & 6,5 & 6,0 \\
6,5 & 7,0 & 9,5 & 8,5 & 9,0 & 7,0 & 7,0 & 7,0 \\
\hline \multicolumn{2}{l}{ Total pré-teste: 54,0} & & & & & \multicolumn{3}{c}{ Média pré-teste $=6,7$} \\
\multicolumn{2}{l}{ Total pós-teste: 64,0} & & & & & Média pós-teste $=7,69$ \\
\hline
\end{tabular}

Se considerarmos a média do grupo controle pós-teste como comparação nos dois grupos para calcularmos a médias pós-teste, obteremos uma diferença de 19\%, como demonstrado:

$$
7,69-6,25 / 6,25 \times 100=19 \%
$$

Os resultados dos pós-testes dos dois grupos foram então submetidos ao teste " $t$ " de Student para pequenas amostras $(\mathrm{n}<30)$ independentes por meio do "software R estatístico" (MILONE, 2004). A comparação das médias foi realizada estatisticamente para verificar se eram significativas considerando as significâncias de 1\% e 5\% para as hipóteses:

$H_{0}: \mu_{1} \neq \mu_{2}$, há diferença significativa entre os grupos.

$\mathrm{H}_{1:} \quad \mu_{1}=\mu_{2}$, não há diferença significativa entre os grupos.

1) Grupo controle: média ( $\left.x_{1}\right)$ igual a 6,25 e desvio padrão $\left(S_{1}\right)$ igual a 1,22

2) Grupo experimental: média $\left(x_{2}\right)$ igual a 7,69 e desvio padrão $\left(S_{2}\right)$ igual a 1,10

O teste bicaudal foi efetuado nos níveis de significância 1\% e 5\%. Os resultados obtidos são apresentados na tabela 3 e indicam com $95 \%$ de confiança que não podemos rejeitar a hipótese $\mathrm{H}_{0}$, ou seja, o livro digital interativo é mais eficiente do que uma aula tradicional no ensino da temática AIDS, já não é possível afirmar essa mesma condição com $99 \%$ de confiança. 
Tabela 3- Resultados dos testes de significância.

\begin{tabular}{cccl}
\hline Valor de T & Nível de significância & Intervalo de confiança & Resultado \\
\hline 2,57 & $5 \%$ & $-2,95<\mathrm{t}<+2,95$ & Não se pode rejeitar $\mathrm{H}_{0}$ \\
\cline { 2 - 4 } & $1 \%$ & $-2,13<\mathrm{t}<+2,13$ & Pode se rejeitar $\mathrm{H}_{0}$ \\
\hline
\end{tabular}

Analisando as resposta à pergunta: "Você já teve na escola informações sobre o tema DST?" identificamos que 9 dos 16 alunos (56,25\%), apontaram que já tiveram. Contudo, 7 alunos (43,75\%) afirmaram que não, demonstrando que, apesar do tema fazer parte da proposta de dois eixos de temas transversais do PCN (Orientação Sexual e a Saúde do indivíduo em processo de formação) (Brasil, 1998) e de estar incluso na maior parte dos livros de Ciências do 8 o ano do ensino fundamental, um número considerável de alunos relatou não terem estudado sobre ele.

Tal fato pode estar relacionado à falta de capacitação dos docentes e gestores para lidarem com a temática, seja por uma formação ineficiente, ou devido à pré- conceitos estabelecidos e receio de questionamentos por parte dos pais e responsáveis pelos alunos, como apontado nessa pesquisa.

A falta de discussão sobre DST no âmbito familiar também foi relatada pelos alunos, pois apenas 6 deles já conversaram com os pais sobre esse tema. Desses 6 alunos, 4 fazem parte do grupo de alunos que também já tiveram informações sobre DST na escola.

Apesar de uma quantidade considerável dos alunos afirmarem não ter recebido informações sobre DST na escola, ainda assim, a instituição é a principal fonte de informações sobre o assunto principalmente se comparada com a família, dado esse semelhante ao encontrado por Gerhardt; Nader; Pereira (2008).

Na questão número 7, que buscou avaliar a eficácia do livro digital interativo junto ao grupo experimental, percebemos que o mesmo teve um impacto positivo, pois nenhum dos estudantes o julgou regular ou ruim. 5 alunos o acharam ótimo e 3 bom.

Sobre a possibilidade de a abordagem do tema a partir do livro interativo ajudar no entendimento do tema AIDS (Questão 8), 6 alunos do grupo experimental declararam que o material foi efetivo, 1 achou parcialmente efetivo e 1 disse que não. Na resposta à questão 9 do pós-teste "Se pudesse modificar o sinal da história, qual seria?" 5 alunos desejaram que ninguém pegasse HIV, 2 não mudariam nada e 1 colocaria uma mensagem diferente no final, mas não mencionou qual.

O fato de o livro digital interativo abordar o conteúdo por meio de uma narrativa similar à de histórias em quadrinhos e também contar com a possibilidade de os alunos interagirem melhor com o material pode ter contribuído para uma aprendizagem mais efetiva, pois proporciona uma maior contextualização do assunto, envolvendo dessa forma o aluno no processo.

Além disso, por se tratar de uma narrativa digital, possui também características que contribuem para o aprendizado, pois consiste numa proposta metodológica que estimula diferentes formas de representação numa perspectiva motivadora, coerente com a aprendizagem construtivista e autônoma, que exige múltiplas competências do sujeito (ALMEIDA; VALENTE, 2012). Tais aspectos tendem a envolver os alunos nativos digitais, uma 
vez que se sentem parte do processo de ensino, podendo efetivamente participar da aula e de forma agradável.

\section{CONCLUSÃO}

A pesquisa demonstrou que o tema DST, incluindo a AIDS, ainda é pouco discutido na escola e nas famílias e que sua abordagem a partir de uma história produzida com auxílio de recursos tecnológicos que possibilitam ao aluno melhor interação com o material colaborou significativamente para a aprendizagem do tema.

O teste estático, $t$ student, demonstrou com $95 \%$ de confiança, que o livro digital interativo foi mais eficaz que a aula expositiva tradicional ministrada ao grupo controle. A aprovação dos alunos em relação ao livro mostra que este recurso é mais interessante e motivador do que uma aula na qual os recursos e métodos utilizados pelos professores já são conhecidos pelos estudantes.

Percebe-se a necessidade de discutir sobre DST com os alunos dentro do espaço escolar. Utilizar o potencial das tecnologias digitais no processo educativo pode possibilitar a criação de novas formas do aluno se relacionar com a informação, principalmente na abordagem de temas polêmicos e muitas vezes pouco discutidos na escola, como questões de comportamento que envolve a sexualidade dos jovens e medidas de prevenção DST. Tal grupo, por falta de informação, se constitui vulnerável e a escola pode e deve se imbuir da responsabilidade de discutir sobre o tema, alertando os alunos sobre os perigos à saúde e sobre como podem se prevenir.

É necessário também aproximar a família dessa discussão, promovendo encontros com os pais em reuniões escolares para que esse assunto e outros relacionados à formação dos alunos para a vida sejam discutidos.

Além de contribuir para a aprendizagem dos usuários do livro "Talentos perdidos", a proposta apresentada também colaborou para a formação dos licenciandos lhes oportunizando, durante a sua formação inicial, vivenciarem a produção, aplicação e avaliação de novas propostas metodológicas. Apesar de se tratar do uso de uma ferramenta de autoria relativamente simples em termos de tecnologia, o PowerPoint na produção de material interativo demonstrou, na avaliação dos alunos, ser um recurso didático satisfatório. Isso nos remete a refletir sobre o quanto nossas escolas precisam evoluir em termos de uso de tecnologias.

Além disso, é necessário incentivar a pesquisa investigativa de novas formas de ensinar, entre elas as calcadas em recursos tecnológicos que envolva professores em formação, afim de, aproximar discentes e docentes em prol de uma aprendizagem mais efetiva de conceitos e habilidades para atuarem na atual sociedade tecnológica.

\section{REFERÊNCIAS BIBLIOGRÁFICAS}


Almeida, M. E. B.; Valente, J. A. (2012, set/dez). Integração currículo e tecnologias e a produção de narrativas digitais. Currículo sem Fronteiras, Porto Alegre, 12 (3), p. 57-82.

Amorim, M.; Bianco, P. (2011). Material didático em mídia digital: transposição de uma apostila do Colégio Dom Bosco para tablet computer. Curitiba: UFPR.

Brasil. Ministério da Educação. Secretaria de Educação Média e Tecnológica (1998). Parâmetros Curriculares Nacionais. Brasília.

Brasil. Programa Internacional de Avaliação de Alunos -PISA. (2010). Results: What Students Know and Can Do: Student Performance in Reading, Mathematics and Science. v.I, OECD Publishing.

Brasil. Ministério da Saúde. Secretaria de Vigilância em Saúde. (2013). Boletim epidemiológicos - HIV/AIDS. Brasília: Departamento de DST, Aids e Hepatites Virais.

Candau, V. M. (1997). Formação Continuada de Professores: tendências atuais. (Org.). Magistério - construção cotidiana. Petrópolis: Vozes.

Demo, P. (2007). Educar pela pesquisa (8a Ed.). Coleção Educação Contemporânea. Campinas. São Paulo: Autores Associados.

Gerhardt, C. R., Nader, S. S., \& Pereira, D. N. (2008). Doenças Sexualmente Transmissíveis: conhecimento, atitudes e comportamento entre os adolescentes de uma escola pública. Revista Brasileira de Medicina de Família e Comunidade, 3(12), 257-270. https://doi.org/10.5712/rbmfc3(12)362

Falkembach, G. A. M. (2005). Concepção e desenvolvimento de material educativo digital. Revista Novas Tecnologias na Educação, 3 (1).

Fey, A. F. (2011, jul). A linguagem na interação professor aluno era digital: considerações teóricas. Revista Tecnologias na Educação, 3 (1).

Galvão, J. (2000). AIDS no Brasil: A agenda da construção de uma epidemia. São Paulo: editora 34.

Garcia, L. A.; Lins, V. S. (2008, Jan./jun.). As tecnologias de informação e comunicação na formação do professor de ensino de ciências. Cadernos de Aplicação, Porto Alegre, 21 (2), p.249-266.

Haag, C. (2012). O que você não quer ser quando crescer? Percepção da Ciência. Pesquisa FAPESP, 192.

Honório, X. M. (2007). O software Microsoft PowerPoint na educação superior: percepções de professores e alunos (Dissertação Mestrado). Universidade Católica de Brasília, Brasília, Brasil.

Lévy, P. (2001). O que é virtual; tradução de Paulo Neves. São Paulo: Editora 34.

Milone, G. (2004). Estatística: geral e aplicada. São Paulo: Pioneira Thomson Learning. 
Minayo, M. C. S.; Deslandes, S. F.; Gomes, R. (2007). Pesquisa social: teoria, método e criatividade. (26a ed.). Petrópolis: RJ: Vozes.

Moran, J. M. (2004). Os novos espaços de atuação do professor com as tecnologias. In: ROMANOWSKI et al. (Org.). Conhecimento local e conhecimento universal: diversidade, mídias e tecnologias na educação. Curitiba: Champagnat, pp. 245-254.

Ponte, J. P. (2002). As TIC no início da escolaridade: Perspectivas para a formação inicial de professores.

Prensky, M. (2001). Digital Natives, Digital Immigrants. On the horizon, MCB University Press, 9 (5), pp. 1-6.

Valle, L.; Bohadana, E. D. B. (2012). Interação e interatividade: por uma reantropolização da EaD online. Educação e Sociedade, Campinas, 33 (121), pp. 973-984.

Yin, R. K. (2001). Estudo de caso Planejamento e métodos. (2a ed.). Porto Alegre: Brookman.

Xavier, A. C.S. (2002). Letramento digital e ensino. Núcleo de Estudos de Hipertexto e tecnologia Educacional- NEHTE. 